\title{
A multifactorial approach to the factors influencing determination of paravertebral depth
}

\author{
[Une approche multifactorielle des facteurs influençant l'évaluation de la \\ profondeur paravertébrale]
}

Jacques E. Chelly MD PhD MBA, Anna Uskova MD, Rita Merman MD, Dorota Szczodry MD

Purpose: Predicting the depth of needle insertion for paravertebral nerve blocks is currently based on patients' anthropometric characteristics, and the block level. Although preliminary studies report relationships between paravertebral depth and the body mass index (BMI), the number of observations, to date, are inadequate to formulate reliable conclusions. This study was designed to determine which factors may predict the distance between the skin and paravertebral space, for patients undergoing paravertebral nerve block procedures.

Methods: After review of peripheral nerve block procedure records, 559 surgical patients who underwent a total of I, 318 thoracic paravertebral nerve blocks for postoperative pain control, were included in the study. The patients' gender, age, weight, height, BMI, thoracic level of the performed block, and depth of the needle insertion were analyzed, using stepwise multiple regression models.

Results: With the exception of T5, a linear relationship was established between paravertebral depth and thoracic level, with depth increasing at inferior thoracic levels. The greatest depth was observed in younger patients with higher BMls. Depth was more variable, and more strongly correlated with age and weight, at levels T4 through T8, compared to levels T9 through TI2. Age had no influence on depth between T9 and TI2. In patients who underwent multiple blocks, awareness of depth of one paravertebral space allowed more accurate prediction of the depth of the other paravertebral spaces.

Conclusion: Age, weight and the thoracic level influence the depth of the paravertebral space between spinal levels T4 and
T8, while only the thoracic level and body weight are implicated between $\mathrm{T} 9$ and $\mathrm{T} I 2$.

CAN J ANESTH 2008/55:9/pp 587-594

Objectif : À l'heure actuelle, la prédiction de la profondeur d'insertion de l'aiguille pour les blocs nerveux paravertébraux se fonde sur les caractéristiques anthropométriques du patient et sur le niveau du bloc. Bien que les études préliminaires rapportent des associations entre la profondeur paravertébrale et l'indice de masse corporelle (IMC), le nombre d'observations est, à ce jour, insuffisant pour émettre des conclusions fiables. Cette étude a été conçue dans le but de déterminer les facteurs pouvant prédire la distance entre l'épiderme et l'espace paravertébral chez les patients traités avec un bloc nerveux paravertébral.

Méthode : Après avoir révisé les dossiers d'interventions de blocs nerveux périphériques, nous avons inclus 559 patients chirurgicaux qui ont subi un total de I 318 blocs nerveux paravertébraux thoraciques pour la prise en charge de la douleur postopératoire. Le sexe, l'âge, le poids, la taille, l'IMC, le niveau thoracique où le bloc a été réalisé et la profondeur d'insertion de l'aiguille ont été analysés à l'aide de modèles de régression multiple progressifs.

Résultats : À l'exception de $T 5$, une relation linéaire a pu être établie entre la profondeur paravertébrale et le niveau thoracique, la profondeur augmentant à des niveaux thoraciques inférieurs. La profondeur la plus importante a été observée chez les patients plus

From the Department of Anesthesiology, ${ }^{*}$ University of Pittsburgh Medical Center and UPMC Shadyside-Presbyterian Hospital, Pittsburgh, Pennsylvania, USA.

Address correspondence to: Dr. Jacques E. Chelly, UPMC Shadyside Hospital, Department of Anesthesiology, Suite M104 (Posner Pain

Center), 5230 Centre Avenue, Pittsburgh, PA 15232, USA. Phone: 412-623-6904; Fax: 412-623-4188; E-mail:chelje@anes.upmc.edu

Competing interests: None declared.

Research sponsored by the Department of Anesthesiology, University of Pittsburgh Medical Center, Pittsburgh, PA, USA.

Accepted for publication March 31, 2008.

Revision accepted June 23, 2008. 
jeunes présentant un IMC plus élevé. La profondeur était plus variable et plus corrélée à l'âge et au poids, de T4 à T8, par rapport à T9 à TI2. L'âge n'a pas eu d'incidence sur la profondeur entre T9 et TI2. Chez les patients ayant subi plusieurs blocs, la connaissance de la profondeur d'un espace paravertébral a permis une prédiction plus précise de la profondeur des autres espaces paravertébraux.

Conclusion : L'âge, le poids et le niveau thoracique influencent la profondeur de l'espace paravertébral entre les niveaux rachidiens T4 et T8, alors que dans le cas de T9 à TI2, seulement le niveau thoracique et le poids jouent un rôle.

$\mathrm{P}$ ARAVERTEBRAL blocks have long been known to be an effective option for perioperative thoracic and abdominal analgesia. Since resurfacing in $1979,{ }^{1}$ interest in this technique has grown tremendously, with a large number of studies having demonstrated the effectiveness and safety of paravertebral blocks. ${ }^{2-4}$ Thoracic paravertebral blocking is technically simple and easy to learn, ${ }^{5,6}$ with a low failure rate ${ }^{5-7}$ and relatively few contraindications. ${ }^{8}$ This regional technique can also be used to provide unilateral somatic and sympathetic blocks, as required, for selected surgical procedures. ${ }^{7,9,10} \mathrm{Ad}-$ ditional postoperative benefits include a reduction in opioid requirements, earlier hospital discharge,${ }^{11}$ and a possible decreased risk for metastases and recurrence following surgery for breast cancer. ${ }^{12}$

Several techniques have been described for entering the paravertebral space, including loss of resistance, nerve stimulator-guided, lateral/intercostal approach, ultrasound assisted, ${ }^{13}$ and even $x$-ray ${ }^{8}$ and CT scan verified approaches. ${ }^{14}$ Although the overall incidence of complications of paravertebral blocks is very low, ${ }^{15,16}$ the risk of pneumothorax and unintended intrathecal injections remain an important clinical concern. The risk of a pneumothorax, which occurs even with the use of a neurostimulation technique ${ }^{17}$ might be minimized if one were able to accurately predict the distance between the skin and the paravertebral space, thereby limiting the risk of puncturing the pleura and the lung. In a preliminary study, Naja et al. ${ }^{18}$ estimated the distance between the skin and the paravertebral space using nerve stimulation technique. Although the authors acknowledge that the number of observations was insufficient to perform a complete analysis, they suggested an association between paravertebral depth and body mass index (BMI). In view of the incomplete information on this subject, we undertook a large cohort study, to determine the predictability of the distance between the skin and paravertebral space, from thoracic spine levels $\mathrm{T} 4$ to $\mathrm{T} 12$, and to evaluate the influence of BMI, weight, height, gender, and age, on the degree of predictability.

\section{Methods}

This retrospective study was approved by the Institutional Review Board of the University of Pittsburgh Medical Center (UPMC). All patients (559) who received single or continuous ( 1,318 in total) paravertebral blocks for postoperative pain control were included in the database. Data from patients who had undergone either thoracic, abdominal, or pelvic surgery at UPMC Presbyterian-Shadyside Hospital, between January 2004 and December 2006, were included in this analysis. All blocks were performed by residents and fellows under the strict supervision of very experienced regional anesthesiologists of the Acute Interventional Perioperative Pain Service (AIPPS) of UPMC Presbyterian-Shadyside Hospital. All blocks were performed using a standardized technique and in every case, a standardized procedure form was used for data collection. In 144 patients $(25.7 \%)$, multiple paravertebral blocks were performed, including 42 patients who received blocks from T4 through T6 spinal levels. Thirty patients received blocks from $\mathrm{T} 7$ through $\mathrm{T} 9$, and 72 patients received blocks from the T10 through T12 spinal levels. Almost all patients (88.9\%) who received blocks between the T10 through T12 levels were male. Prior to this study, using a radiographic distribution of a contrast dye, we established that our blind technique ${ }^{\mathrm{A}}$ was associated with a similar success rate in identifying the paravertebral space, as compared to the use of a nerve stimulator technique. ${ }^{19}$

\section{General procedure}

All patients were assessed by an AIPPS anesthesiologist, and informed consent for the procedure was obtained prior to the block. Supplemental oxygen was provided with nasal cannulae. Routine monitors were applied, and the patients were placed in the sitting position for the block procedure. First, the predominance of C7 spinous process and the lowest angles of the scapulae (corresponding to T7 spinous process) were identified. Next, the appropriate level(s) for the block was determined, and the upper border of the spinous process was marked. The site of needle introduction was 2.5 $\mathrm{cm}$ laterally from the midline. Skin was widely prepped

A Matusic BP, Anthikad F, Ben-David B, Chelly JE. Imaging of continuous paravertebral catheters. Presented at the Annual Meeting of the American Society of Anesthesiologists, Chicago, 2006. 
TABLE I Patients characteristics $(n=559)$.

\begin{tabular}{ll}
\hline Characteristic & Mean \pm SD except where specified \\
Sex $($ female/male $)(n)$ & $202 / 357$ \\
Age $(\mathrm{yr})$ & $60.4 \pm 14.1$ \\
Height $(\mathrm{cm})$ & $171.3 \pm 10.3$ \\
Weight $(\mathrm{kg})$ & $81.0 \pm 17.6$ \\
BMI $\left(\mathrm{kg} \cdot \mathrm{cm}^{-2}\right)$ & $27.6 \pm 5.8$ \\
\hline
\end{tabular}

$\mathrm{BMI}=$ body mass index.

with chlorhexidine, and 1\% lidocaine was used to anesthetize the skin and subcutaneous tissue with a $24 \mathrm{G}$ $3.75 \mathrm{~cm}$ needle. A graduated Tuohy needle was used to perform the blocks: $22 \mathrm{G} 7.9 \mathrm{~cm}$ (B.Braun Medical, Bethlehem, PA, USA) needles for single shot blocks, and $18 \mathrm{G}, 8.9 \mathrm{~cm}$ needles (B.Braun Medical, Bethlehem, PA, USA) for continuous blocks. The needle was advanced perpendicularly to the skin, in search of the transverse process $(\mathrm{TP}) .^{20}$ After appropriate contact with the TP, which was achieved in every patient, the depth between the skin and TP was measured, and the needle was withdrawn to the skin, reintroduced caudad, and advanced $1 \mathrm{~cm}$ beyond the TP. This defined the depth of the paravertebral space. After negative aspiration, $5 \mathrm{~mL}$ of $0.5 \%$ ropivacaine was injected through the needle. For continuous block, a 20G multiorifice catheter was advanced up to $5 \mathrm{~cm}$ into the paravertebral space, and, after confirming negative aspiration, an additional $10 \mathrm{~mL}$ of ropivacaine was injected, in $5 \mathrm{~mL}$ increments. Following each procedure, each patient was assessed by the AIPPS anesthesiologist, according to the clinical protocol which was established.

\section{Statistical analysis}

SELECTION AND PARAMETERIZATION OF PREDICTORS

Correlations among all possible predictors other than thoracic level (age, height, weight, BMI, gender) were tested for statistical significance. Correlations between candidate predictors and paravertebral depth were also calculated, as well as partial correlations with paravertebral depth, controlling for thoracic level. To assess departures from a linear functional form, centered quadratic terms for each of the retained continuous predictors (weight, height, age, and thoracic level) were investigated. In no instance were these terms significant $(P>0.05$ for each). In the case of the thoracic level, we tested whether there was a more statistically efficient representation of the thoracic level than a fully categorical representation, investigating the combination of a linear term and a T5 indicator to capture the departure of linearity at this location.

\section{MULTIVARIABLE MODELS}

After retaining only the most bivariately predictive of
TABLE II Correlations of the different predictors with the depth of the paravertebral space

\begin{tabular}{lll}
\hline Predictor & $\begin{array}{l}\text { Correlation } \\
\text { with depth }^{a}\end{array}$ & $\begin{array}{l}\text { Partial correlation with } \\
\text { depth, controlling for } \\
\text { thoracic level }^{b}\end{array}$ \\
\hline Age $(\mathrm{yr})$ & -0.15 & -0.18 \\
Female & -0.21 & -0.06 \\
Height $(\mathrm{cm})$ & 0.21 & 0.12 \\
Weight $(\mathrm{kg})$ & 0.35 & 0.33 \\
BMI $\left(\mathrm{kg} \cdot \mathrm{cm}^{-2}\right)$ & 0.25 & 0.29 \\
Thoracic level (T4-T12) & $0.53^{\mathrm{c}}$ & $\mathrm{N} / \mathrm{A}$ \\
\hline
\end{tabular}

${ }^{\mathrm{a}} \mathrm{P}<0.0001$ for all reported correlations, with the exception of the value for female in the second column, for which $P=0.024$; ${ }^{\mathrm{b}} \mathrm{T} 4-\mathrm{T} 12$ represented by a single linear term;

'This represents the square root of the $\mathrm{R}^{2}$ in a linear regression predicting depth by thoracic level.

highly correlated candidate predictors, and eliminating nonsignificant predictors from preliminary multivariable models $(P>0.05)$, we investigated two-way interactions among predictors. All multivariable models correct for the clustering of multiple paravertebral locations within patients. ${ }^{21}$ Because of interactions of patient characteristics with thoracic location, the primary models presented stratify by thoracic location (Models $\mathrm{la}$ and $\mathrm{Ib}$ predict T4 through T8 and T9 through T12, respectively, from age, weight, linear thoracic level and a T5 location indicator (Model la only). This split by levels minimized the interactions of location with age and weight, within the stratified models. A final pair of models (Models 2a and $2 \mathrm{~b}$ not shown) was restricted to individuals who received multiple paravertebral blocks, and added unique patient identifiers as variables to Models $l a$ and $l b$, respectively. Models $2 \mathrm{a}$ and $2 \mathrm{~b}$ accounted for any variation that is consistent within individuals, and which would be represented by unmeasured relevant individual characteristics after accounting for age, weight, and thoracic levels, and can be used to improve predictions within individuals for whom one paravertebral depth is known. The residuals of multivariable models were assessed for normality. ${ }^{22}$ The predictive accuracy of multivariable models was assessed via tenfold crossvalidated $R^{2}{ }^{23}$

\section{Results}

The data consist of 1,318 observations from thoracic levels T4 through T12. The paravertebral depth ranged from 1.0 to $8.5 \mathrm{~cm}$ (mean of $4.8 \mathrm{~cm} \pm 1.4 \mathrm{~cm}$; median of $5 \mathrm{~cm}$ ). Patient characteristics appear in Table I.

\section{Bivariable trends in paravertebral depth}

Table II describes the bivariable correlation of each independent variable with paravertebral depth, pooling across all locations from T4 through T12 (col- 


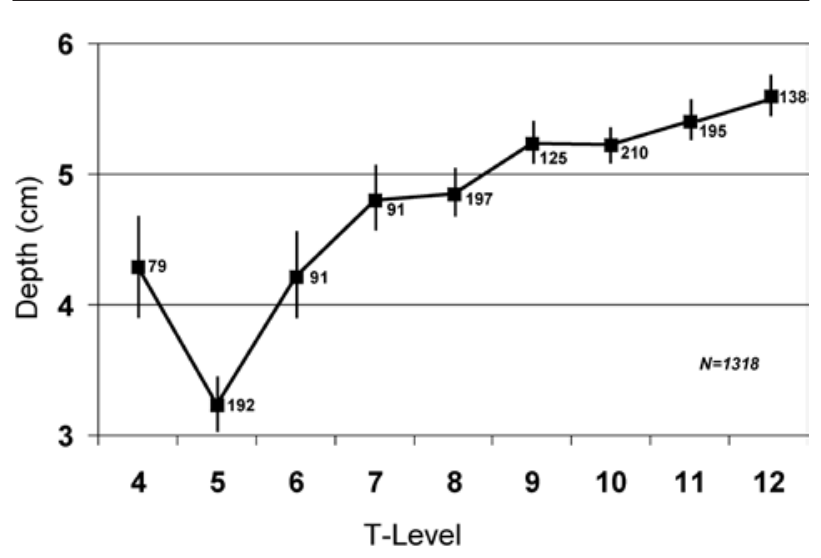

FIGURE 1 Mean paravertebral depth [95\% CI] by thoracic level and number of observations at each level, between T4 and T12.

umn 1) and the partial correlation of factors, other than thoracic location, with paravertebral depth after controlling for thoracic level with a linear term (column 2). All correlations and partial correlations were statistically significant $(P<0.001$ for all, but the partial correlation of female, for which $P=0.024$ ), with greater paravertebral depth for individuals who were heavier, taller, and with higher BMI. The depth was also greater for men and for younger patients $(P<0.001)$. As can be seen in the first column of Table II, the thoracic level was the most important bivariable predictor of depth, followed by weight and BMI. Height and gender appeared to be important before accounting for the thoracic level $\left(\mathrm{R}^{2}=0.21\right.$ for both, $P<0.001)$, but both were less important than age $\left(\mathrm{R}^{2}=-0.18, P<0.001\right.$ for age; $\mathrm{R}^{2}=0.12, P<0.001$ for height; $\mathrm{R}^{2}=-0.06, P=0.024$ for female) after considering the thoracic level.

All pairwise correlations among candidate predictors were below the standard threshold of 0.8 in absolute value, ${ }^{24}$ with the exception of the correlation of 0.82 between BMI and weight $(P<0.001)$. This collinearity required that only one of the pair of BMI and weight may be included in multivariable models, so we retained only the predictor with the higher bivariable correlation with the outcome of paravertebral depth (weight), excluding BMI from further consideration; later sensitivity tests confirmed this exclusion. A preliminary model of paravertebral depth achieved adequate fit with a linear term for thoracic level, plus an indicator variable for $\mathrm{T} 5$ to account for the departure from the linear trend evident in Figure 1 .

\section{Multivariable models of paravertebral depth}

Preliminary multivariable models (not shown), found no significant effect of height or gender $(P=0.604$ and 0.842 , respectively) and that linear thoracic location interacted significantly with both age and weight $(P=0.043$ and $P<0.001$, respectively) and the T5 indicator interacted significantly with weight $(P=0.002)$. These interactions indicated smaller effects of age and weight at T9 through T12, as compared to T4 through T8 and a smaller effect of weight at T5 than at T4 and T6 through T8. The model of thoracic location, age, and weight was stratified by thoracic location (T4 through T8 vs T9 through T12), referred to as Model la and $1 \mathrm{~b}$, respectively. The residuals of these models were consistent with a normal distribution. ${ }^{22}$

Models la and $\mathrm{lb}$ appear in Table III. First, these models indicate that the depth varies by level, more within T4 through T8, than within spinal levels T9 through T12. Second, the effects of age and weight are about three times as large within T4 through T8 as within $\mathrm{T} 9$ through $\mathrm{T} 12$, with age not having a significant effect between T9 and T12. At T4 through T8, depth increases by $0.031 \mathrm{~cm} \cdot \mathrm{kg}^{-1}$ and decreases by $0.015 \mathrm{~cm}$ per year. At T9 through T12, depth increases by $0.011 \mathrm{~cm} \cdot \mathrm{kg}^{-1}$. The use of these models led to a higher tenfold cross-validated R2, for T4 through T8 $(34 \%)$ than for T9 through T12 (7\%), but with less error in absolute terms for T9 through T12 (a cross-validated residual standard deviation of $0.9 \mathrm{~cm}$ ) than for T4 through T8 (a residual standard deviation of $1.3 \mathrm{~cm}$ ). These residual standard deviations are the average expected error for a prediction for an individual with no previous measurements. ${ }^{\mathrm{B}}$ This means that between T4 and T8, the depth of the paravertebral space is shallower, more variable, and moderately related to both age and weight, whereas for T9 through T12, the depth of the paravertebral space is deeper, less variable, and slightly related to weight but not to age.

\section{Prediction from age, weight, and thoracic location using models $1 a$ and 16}

Figure 2 illustrates the predictions of paravertebral depth at T4 through T12 from Models la and Ib at 49 combinations of weight $(50,60,70,80,90,100$, and $110 \mathrm{~kg})$ and age $(20,30,40,50,60,70$, and 80 yr).

B Average prediction varies slightly within the range of predictor values as a function of the standard error of the predicted mean, but this component never adds more than $0.04 \mathrm{~cm}$ to the values above, at any values within the observed ranges of age and weight. 
TABLE III Models of average depth stratified by thoracic level (Models la and 1b)

\begin{tabular}{|c|c|c|c|c|c|c|}
\hline & \multicolumn{3}{|c|}{ Model la: T4 through T8 } & \multicolumn{3}{|c|}{ Model 1b: T9 through T12 } \\
\hline & Coefficient & (Standard error) & $P$-value & Coefficient & (Standard error) & $P$-value \\
\hline Thoracic level & 0.165 & $(0.046)$ & $<0.001$ & 0.122 & $(0.038)$ & 0.002 \\
\hline Age (yr) & -0.015 & $(0.004)$ & $<0.001$ & -0.005 & $(0.004)$ & 0.140 \\
\hline Weight (kg) & 0.031 & $(0.004)$ & $<0.001$ & 0.011 & $(0.003)$ & 0.001 \\
\hline Intercept & 1.956 & $(0.457)$ & $<0.001$ & 3.493 & $(0.618)$ & $<0.001$ \\
\hline \multicolumn{7}{|c|}{ Cross-validated measures } \\
\hline \multicolumn{2}{|l|}{$\mathrm{R}^{2}$} & $35 \%$ & & \multicolumn{3}{|c|}{$6 \%$} \\
\hline \multicolumn{2}{|c|}{ Residual standard deviation } & $1.3 \mathrm{~cm}$ & & \multicolumn{3}{|c|}{$0.9 \mathrm{~cm}$} \\
\hline
\end{tabular}

Prediction from age, weight, thoracic location, and a previous measurement for the same individual

The final pair of Models ( $2 \mathrm{a}$ and 2b, not shown), which was restricted to individuals having multiple paravertebral blocks and which added unique identifiers, increased the tenfold cross-validated $\mathrm{R}^{2}$ from $34 \%$ to $97 \%$ for T4 through T8, and from $7 \%$ to $51 \%$ for T9 through T12, reducing the cross-validated residual standard errors to $0.5 \mathrm{~cm}$ for T4 through T8 and to $0.7 \mathrm{~cm}$ for T9 through T12. These results suggest that a measurement of the depth of the paravertebral space at one thoracic level for a given patient substantially improves the prediction of the paravertebral depth at a second and third level, so that average prediction errors of less than $1 \mathrm{~cm}(0.5-0.7 \mathrm{~cm})$ can be expected. These results imply a prediction formula given one paravertebral measurement within the same set (T4 through T8 or T9 through T12). Let $a$ be the first paravertebral measurement, and let $b$ be the prediction of that depth from Model la or $1 \mathrm{~b}$ (according to the location), using the patient's age, weight, and the first location measured. It can be shown that the adjustment factor $d$ for predicting depth at the second location is $d=c^{*}(a-b)$, where $c=0.98$ for T4 through T8 and $c=0.69$ for T9 through T12. When predicting the second location for the same individual using Models la or $1 \mathrm{~b}$, one would input the same age and weight, the new location, and then add the adjustment factor $d$ to that model's prediction.

\section{Discussion}

This study modeled the depth of the paravertebral space in patients who had previously received thoracic paravertebral nerve blocks. Our analysis demonstrated that higher variability, and more predictive factors at the mid $v s$ lower thoracic level, may minimize the utility of depth prediction for this important anatomic region. Our study also demonstrated that, when multiple paravertebral blocks are required in the same patients, establishing the depth of the paravertebral space at one level greatly facilitated an accurate prediction of the depth of the other paravertebral spaces, with an error of $0.5 \mathrm{~cm}$ (T4 through T8) to $0.7 \mathrm{~cm}$ (T9 through T12).

Administration of local anesthetic mixture, either directly or indirectly via the placement of a catheter, has been described using several techniques, including direct access of the paravertebral space during a thoracotomy. ${ }^{25,26}$ Other indirect approaches include the use of a nerve stimulator ${ }^{18}$ and/or loss of resistance, with and without pressure monitoring, ${ }^{27}$ and a blind technique. ${ }^{20}$ Boezaart et $a l^{28}$ indicated that "nerve stimulation is probably not essential for successful thoracic paravertebral block". Although our data seems support such a concept, it is clear that additional studies are still required to compare paravertebral techniques, and to establish the most reliable and safest approach.

Using a nerve stimulation technique, Naja et al. ${ }^{18}$ reported a relationship between the paravertebral depth and BMI. According to these authors, the variability was not affected by the spinal level, and the depth of the paravertebral space was the least between spinal levels T5 and T6. Our larger data set established the importance of weight and age, especially between $\mathrm{T} 4$ to $\mathrm{T} 8$, and the importance of body weight between T9 to T12. Furthermore, at T5, we observed less depth than predicted by a linear model. Our results suggest that the previously noted relationship between depth and BMI were better captured using weight; we also found no independent effect of height after consideration of weight.

Although we confirmed that depth varied according to thoracic level, and that there was a general trend for greater depth for $\mathrm{T} 9$ through $\mathrm{T} 12$, our data showed longer distances from the skin to the paravertebral space, compared to those using a neurostimulation technique..$^{3,8,18}$ Since we reported that the use of a blind technique led to a spray of dye anterior to the endothoracic fascia, at least as often as with the use of a neurostimulation approach, the difference between our results and those previously published 

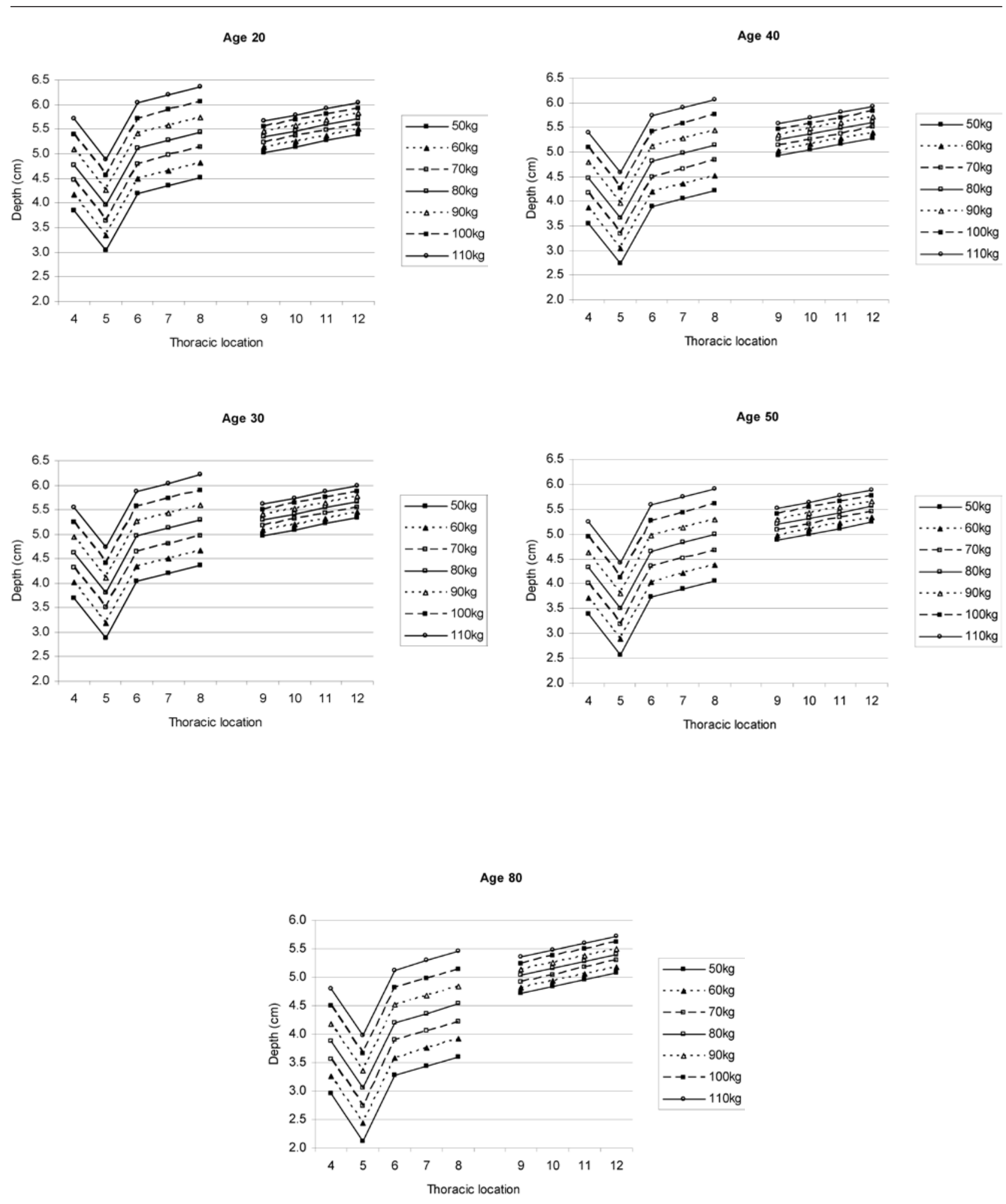

FIGURE 2 Illustration of the effects of weight $(110,100,90,80,70,60$, and $50 \mathrm{~kg})$ and age $(20,30,40,50,60,70$ and $80 \mathrm{yr})$ on the depth of the paravertebral space between T4 and T12 (Models la and lb). 
may be attributed to differences in anthropometric characteristics of the patients included in these studies. On average, our patients had higher BMIs compared to those subjects included in previously published studies.

There are several relevant clinical implications of these findings. First, for the purpose of paravertebral blocks, the depth of the thoracic paravertebral space can be divided into a high thoracic (T4 through T8), and a low thoracic region (T9 through T12). Second, in the high thoracic region, the depth of the paravertebral space is characterized by relative unpredictability (average prediction errors of $1.3 \mathrm{~cm}$ vs 0.9 $\mathrm{cm}$ for the low thoracic region) and dependence on thoracic level, gender, age, and weight. Third, in the high thoracic region, the depth of the paravertebral space increases approximately $1 \mathrm{~cm}$ per $32 \mathrm{~kg}$, and decreases approximately $1 \mathrm{~cm}$ per $67 \mathrm{yr}$ of patient age. In contrast, in the lower region, the depth of the paravertebral space is more predictable, and depends only on the thoracic level, and patient weight. In this latter region, we demonstrated that the depth of the paravertebral space increases approximately $1 \mathrm{~cm}$ per $91 \mathrm{~kg}$ body weight.

One interpretation is that more prudence is warranted when attempting to locate the paravertebral space in the high thoracic region, not only because the risk of pneumothorax is higher when performing paravertebral blocks in the high thoracic region $v s$ the lower thoracic region, but also because of the demonstrated high variability at which the paravertebral space can be located. In this regard, the data in Figure 2, showing the effects of thoracic level, age, and weight on the relative distribution of the depth of the paravertebral space of the high and low thoracic region, may serve as a guide to facilitate the performance of paravertebral blocks, for both experienced, and less experienced, practitioners.

As for any cohort study, there are methodological limitations, which must be considered. One limitation is the fact that the analysis did not include data for thoracic levels $\mathrm{Tl}$ through $\mathrm{T} 3$, because in our practice, we rarely are required to perform paravertebral blocks at these levels. Furthermore, since only a limited number of multiple paravertebral blocks were performed in the same patients $(25.7 \%)$, it is important to recognize that the proposed predictive modeling of the depth of consecutive paravertebral spaces (based on the depth of the first paravertebral space) requires confirmation with a larger sample size.

In conclusion, the usefulness of developing models to predict the depth of the paravertebral space appears to be of limited value because, in the higher thoracic region, which is associated with the higher risk of pneumothorax (T4 through T8), we demonstrated that a complex relationship exists between the depth of the paravertebral space, the thoracic level, age, gender and weight, as well as a high variability. Furthermore, in the lower thoracic levels (T9 through T12), the paravertebral depth is more predictable, and only affected by the thoracic level and body weight.

\section{References}

1 Eason MJ, Wyatt R. Paravertebral thoracic block - a reappraisal. Anaesthesia 1979; 34: 638-42.

2 Sabanathan S, Richardson J, Mearns AJ. Management of pain in thoracic surgery. Br J Hosp Med 1993; 50: 114-20.

3 Pusch F, Freitag H, Weinstabl C, Obwegeser R, Huber $E$, Wildling $E$. Single-injection paravertebral block compared to general anesthesia in breast surgery. Acta Anaesthesiol Scand 1999; 43: 770-4.

4 Naja Z, Ziade MF, Lonnqvist PA. Bilateral paravertebral somatic nerve block for ventral hernia repair. Eur J Anaesthesiol 2002; 19: 197-202.

5 Kirvela $O$, Antila $H$. Thoracic paravertebral block in chronic postoperative pain. Reg Anesth 1992; 17: 348-50.

6 Coveney E, Weltz CR, Greengrass R, et al. Use of paravertebral block anesthesia in the surgical management of breast cancer: experience in 156 cases. Ann Surg 1998; 227: 496-501.

7 Tenicela R, Pollan SB. Paravertebral-peridural block technique: a unilateral thoracic block. Clin J Pain 1990; 6: 227-34.

8 Richardson J, Lonnqvist PA. Thoracic paravertebral block. Br J Anaesth 1998; 81: 230-8.

9 Saito T, Gallagher ET, Yamada K, Tanuma K, Ogawa $R$. Broad unilateral analgesia. Reg Anesth 1994; 19: 360-1.

10 Saito T, Gallagher ET, Cutler S, et al. Extended unilateral anesthesia. New technique or paravertebral anesthesia? Reg Anesth 1996; 21: 304-7.

11 Ben-David B, Swanson J, Nelson JB, Chelly JE. Multimodal analgesia for radical prostatectomy provides better analgesia and shortens hospital stay. J Clin Anesth 2007; 19: 264-8.

12 Exadaktylos AK, Buggy DJ, Moriarty DC, Mascha E, Sessler DI. Can anesthetic technique for primary breast cancer surgery affect recurrence of metastasis? Anesthesiology 2006; 105: 660-4.

13 Pusch F, Wildling E, Klimscha W, Weinstabl C. Sonographic measurement of needle insertion depth in paravertebral blocks in women. Br J Anaesth 2000; 85: 841-3.

14 Lonnqvist PA, Hesser U. Radiological and clinical distribution of thoracic paravertebral blockade in 
infants and children. Pediatr Anaesth 1992; 47:

1051-2.

15 Lonnqvist PA, MacKenzie J, Soni AK, Conacher ID.

Paravertebral blockade. Failure rate and complications. Anaesthesia 1995; 50: 813-5.

16 Richardson J, Sabanathan S. Thoracic paravertebral analgesia. Acta Anaesthesiol Scand 1995; 39: 1005-15.

17 Karmakar MK. Thoracic paravertebral block. Anesthesiology 2001; 95: 771-80.

18 Naja MZ, Gustafsson AC, Ziade MF, et al. Distance between the skin and the thoracic paravertebral space. Anaesthesia 2005; 60: 680-4.

19 Naja MZ, Ziade MF, El Rajab M, El Tayara, Lonnqvist $P A$. Varying anatomical injection points within the thoracic paravertebral space: effect on spray of solution of nerve blockade. Anaesthesia 2004; 59: 459-63.

20 Casati A, Alessandrini P, Nuzzi M, et al. A prospective, randomized, blinded comparison between continuous thoracic paravertebral and epidural infusion of $0.2 \%$ ropivacaine after lung resection surgery. Eur J Anaesthesiol 2006; 23: 999-1004.

21 Williams $R L$. A note on robust variance estimation for cluster-correlated data. Biometrics 2000; 56: 645-6.

22 Jarque CM. "Efficient tests for normality, homoscedasticity and serial independence of regression residuals”. Econ Lett 1980; 6: 255-9.

23 Picard RR, Cook RD. Cross-validation of regression models. Journal of the American Statistical Association 1984; 79: 575-83.

24 Berry WD, Feldman S. Multiple Regression in Practice. CA: Sage; 1985: 37-50.

25 Luketich JD, Land SR, Sullivan EA, et al. Thoracic epidural versus intercostal nerve catheter plus patientcontrolled analgesia: a randomized study. Ann Thorac Surg 2005; 79: 1845-9.

26 Marret E, Bazelly B, Taylor G, et al. Paravertebral block with ropivacaine $0.5 \%$ versus systemic analgesia for pain relief after thoracotomy. Ann Thorac Surg 2005; 79 : 2109-13.

27 Richardson J, Cheema SPS, Hawkins J, Sabanathan S. Thoracic paravertebral space location: A new method using pressure measurement. Anaesthesia 1996; 51: 137-9.

28 Boezaart AP, Raw RM. Continuous thoracic paravertebral block for major breast surgery. Reg Anesth Pain Med 2006; 31: 470-6. 